\title{
A Novel Fault Location Algorithm for Multi-Terminal Lines Using Phasor Measurement Units
}

\author{
Kai-Ping Lien, Student Member, IEEE, Chih-Wen Liu, Senior Member, IEEE, \\ Joe-Air Jiang, Member, IEEE, Ching-Shan Chen, and Chi-Shan Yu, Member, IEEE
}

\begin{abstract}
This paper presents a new PMU-based fault location algorithm for EHV multi-terminal transmission lines. The development of the algorithm is based on distributed transmission line model and synchronized positive sequence voltage and current phasors. The method does not require fault type identification and its computational cost is very low since it does not require iterative operations. The EMTP/ATP simulator was adopted to verify the accuracy of the method. The simulation studies show that the algorithm provides a high degree of accuracy in fault location. The algorithm is independent of various fault and system conditions such as fault types, fault positions, fault path resistance, pre-fault load flows, and line shunt capacitance, etc.
\end{abstract}

Index Terms - fault location, gobal positioning system (GPS), phasor measurement units (PMUs), transmission lines.

\section{INTRODUCTION}

$\mathrm{T}$ ransmission line faults have to be located quickly and accurately in order to repair the faulted section, restore power delivery, and reduce outage time as soon as possible. Therefore, the development of a robust and accurate fault location technique under various normal and fault conditions is a highly important research area. Many digital algorithms have been presented to locate faults [1]-[11]. Single-end, impedance-based fault location technique is very attractive because it is simple and does not require communications [1]. The reactance method works well when the fault does not involve significant fault resistance and load current [2]. The accuracy of single-ended fault locators is affected by various assumptions that are made about the fault resistance, the source impedance, the remote in-feed current, and the line model, etc [1].

With the current trend towards multi-terminal power transmission lines, one-terminal location systems are of limited use because they are unable to determine whether or not a fault which lies beyond point is a branch line fault.

Digital relays and communication systems provide the opportunity to perform fault location using data from both

Kai-Ping Lien and Chih-Wen Liu are with Department of Electrical Engineering, National Taiwan University, Taipei, Taiwan. (e-mail: f89921115@ntu.edu.tw and cwliu@cc.ee.ntu.edu.tw)

Joe-Air Jiang is with the Department of Bio-Industrial Mechatronics Engineering, National Taiwan University, Taipei, Taiwan. (e-mail: jajiang(a)ntu.edu.tw)

Ching-Shan Chen is with the Industrial Technology Research Institute, Hsinchu, Taiwan. (e-mail: JohnsonChen@itri.org.tw)

Chi-Shan $\mathrm{Yu}$ is with National Defense University, Chung-Cheng Institute of Technology, Taiwan. (e-mail: chsyu@ccit.edu.tw) ends in transmission lines. Therefore, the fault location can be estimated with minimal assumptions and sources of error. Since low-speed communication channels are often available, the fault data can be transmitted to a central site or communicated between digital relays or other devices for accurate fault location.

The authors have proposed an approach for fault location in a two-terminal transmission line [10], [11]. Since the new rights of way for transmission lines are difficult to obtain in Taiwan, a lot of multi-terminal transmission lines exist in Taiwan power system. Therefore, based on our previous researches, we develop an innovative fault location algorithm for multi-terminal lines. The new approach is very simple such that only the positive sequence line parameters and phasors at the ends of transmission lines are required to be known for algorithm implementation. The proposed method is very robust and not affected significantly by various system and fault conditions.

\section{The Proposed Fault Location Algorithm}

The principles of the new PMU-based fault location algorithm for transmission lines are described in this section. The paper starts with two-terminal transmission lines to explain the basic principles and then extends the techniques to three-terminal and other multi-terminal lines.

\section{A. The fault location algorithms for two-terminal transmission lines}

Fig. 1 shows a single-circuit transposed transmission line. In [10]-[11], the authors utilize Clarke transformation to decouple the inter-phase quantities and then a fault location technique is developed using two-terminal synchronized phasors and distributed line model. In this paper, we adopt the symmetrical components transformation to resolve the coupling effect among the inter-phases. Since the positive sequence quantity appears in all fault types, this quantity is used in the fault location algorithm. Therefore, the developed algorithm does not require fault type identification, which avoids possible problems due to incorrect fault type discrimination. As shown in fig. 1, the per-unit fault location $\mathrm{D}$ can be solved by the following equation [10]:

$$
\mathrm{D}=\frac{\ln (\mathrm{N} / \mathrm{M})}{2 \Gamma \mathrm{L}}
$$

where $\mathrm{M}$ and $\mathrm{N}$ are expressed as 


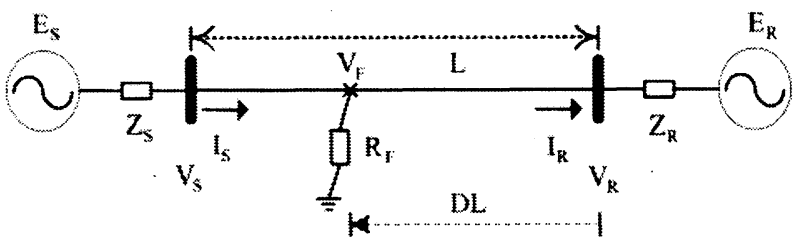

Fig. 1. One-line diagram of a signal-circuit transmission line.

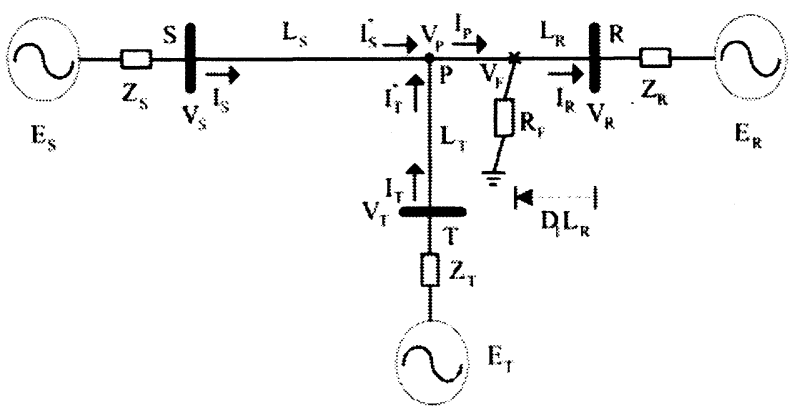

Fig. 2. One-line diagram of a three-terminal transmission line under a fault occurs in $L_{R}$.

$$
\begin{aligned}
& M=\frac{1}{2} e^{-\Gamma L}\left[V_{S}+Z_{C} I_{S}\right]-\frac{1}{2}\left[V_{R}+Z_{C} I_{R}\right] \\
& N=\frac{1}{2}\left[V_{R}-Z_{C} I_{R}\right]-\frac{1}{2} e^{\Gamma L}\left[V_{S}-Z_{C} I_{S}\right]
\end{aligned}
$$

where $\mathrm{L}$ is the total length of the transmission line, $\Gamma$ and $\mathrm{Z}_{\mathrm{C}}$ are positive sequence propagation constant and surge impedance respectively, and $V_{R}, V_{S}, I_{R}, I_{S}$ are the synchronized positive sequence phasors of receiving end/sending end voltages and currents, respectively.

Since the line shunt capacitance is considered in the line model, the fault location algorithm is very suitable for long distance transmission lines. Moreover, the effect of fault path resistance is completely eliminated using two-terminal measurements. Extensive simulation studies show the performance of the proposed fault location algorithm for a single-circuit transmission line is very excellent under various power system and fault conditions [11].

\section{B. The fault location algorithms for three-terminal transmission lines}

Consider a three-terminal line as depicted in fig. 2. The PMUs are installed at buses S, R, and T. Therefore, we can obtain three-terminal synchronized voltage and current phasors. There are three possible faulted line sections, which are $L_{R}, L_{S}$, and $L_{T}$ as shown in fig. 2 .

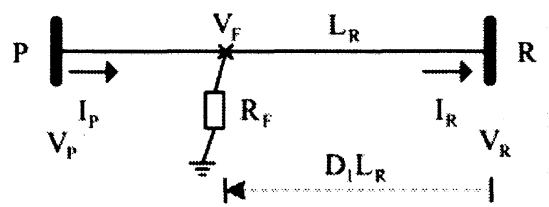

Fig. 3. The reduced two-terminal system from a three-terminal line system.
Since we have three synchronized phasors of Bus R, S, and $\mathrm{T}$, we can reduce this three-terminal line into twoterminal line and apply the two-terminal fault location algorithm [10]. First, we random choose bus $\mathrm{R}$ as the reference bus. Then, the node $P$ can be thought as bus $P$ and the voltage at node $P$ can be calculated from bus $S$ and $T$ respectively. The analysis of the fault case can be reduced to the two-terminal line system as shown in fig. 3. It will produce both indices $D_{1}$ and $D_{2}$. The detailed proof is shown in Appendix [12].

Therefore, the two-terminal fault location algorithm described previously can be used to derive the fault location indices. Both of the indices $D_{1}$ and $D_{2}$ can be applied to locate faults occurring in $\mathrm{L}_{R}, \mathrm{~L}_{\mathrm{S}}$, and $\mathrm{L}_{\mathrm{T}}$. There are special relationships between the two indices $D_{1}$ and $D_{2}$. They can be used to identify the faulted line section and locate faults. The relationships are as follows:

(1) $0<D_{1}<1$ and $0<D_{2}<1$ : the fault occurs in $L_{R}$. Then, $D_{1}=D_{2}$, and both of them are accurate fault locations.

(2) $D_{1}>1$ and $D_{2}=1$ : the fault occurs in $L_{S}$ and $D_{1}$ is the actual fault location away from bus $R$.

(3) $D_{1}=1$ and $D_{2}>1$ : the fault occurs in $L_{T}$ and $D_{2}$ is the actual fault location away from bus $\mathrm{R}$.

(4) $D_{1}=1$ and $D_{2}=1$ : the fault occurs in point $P$.

In summary, the proposed algorithm first assumes that a fault occurs in line $L_{R}$ and then the two fault location indices $D_{1}$ and $D_{2}$ are obtained. When the fault occurs in $L_{R}$, the values of $D_{1}$ and $D_{2}$ are the exact fault location. If the fault does not occur in $L_{R}$, then we can discriminate the faulted line section through the logic mentioned above and accurately locate the fault using $\mathrm{D}_{1}$ and $\mathrm{D}_{2}$. Through the proposed method, the faulted line section is correctly determined and the fault point is accurately located in a reliable and simple manner.

\section{The fault location algorithms for multi-terminal transmission lines}

The technique can easily extend to other multi-terminal transmission lines. For example, consider a five-terminal line as depicted in fig. 4. The PMUs are installed at buses R, $1,2,3$, and 4 . Therefore, we can obtain five-terminal synchronized voltage and current phasors. There are seven possible faulted line sections, which are $\mathrm{L}_{\mathrm{R}}, \mathrm{L}_{1}, \mathrm{~L}_{2}, \mathrm{~L}_{3}, \mathrm{~L}_{4}$, $L_{12}$, and $L_{23}$ as shown in fig. 4. Similarly, we can extend the techniques in Appendix to derive the fault location indices

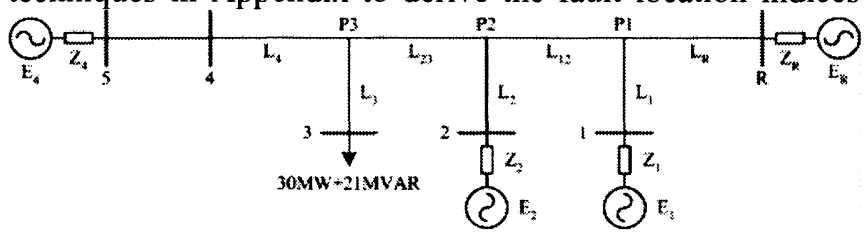

Fig. 4. One-line diagram of a five-terminal transmission line. 
$D_{1}, D_{2}, D_{3}$, and $D_{4}$. The indices $D_{1}, D_{2}, D_{3}$, and $D_{4}$ can be applied to discriminate and locate faults occurring in $\mathrm{L}_{\mathrm{R}}, \mathrm{L}_{1}$, $L_{2}, L_{3}, L_{4}, L_{12}$, and $L_{23}$. There are four special relationships between the indices to identify the faulted line section and locate faults. The relationships are as follows:

(1) If all fault location indices are equal to each others and fall into $(0,1)$, the fault occurs in $L_{R}$.

(2) If $D_{k}$ is the maximum indices. The fault occurs in section Bus $k-P k$ (the nearest tap point) and $D_{k}$ is the actual fault location away from bus $\mathrm{R}$.

(3) If the fault location indices $D_{k}, D_{k+1}, \ldots$ and $D_{4}$ are equal and bigger than the remaining indices, the fault occurs between tap points $P(k-1)$ and $P k$, where $D_{k}$ is the actual fault location away from bus $\mathrm{R}$.

(4) If all indices do not converge, the fault is identified as an external fault.

Using the proposed method, the faulted line section can be correctly discriminate and the fault also can be accurately located in a reliable and simple manner.

\section{Performance Evaluation}

To verify the performance of the proposed fault location algorithm, the EMTP/ATP simulator was used to generate the fault data [13].

\section{A. System modeling}

A $345 \mathrm{kV}, 60 \mathrm{~Hz}$ transposed five-terminal transmission line was modeled as shown in fig. 4 . The simulated system can be used to demonstrate the correctness of the mentioned fault location algorithms for transmission lines. The related parameters of the simulated system are shown in Table I. The transmission line parameters are obtained using EMTP LINE CONSTANTS program [13] based on related tower data encountered in Taiwan. The sampling frequency is $1920 \mathrm{~Hz}$ (32 sampling points per cycle). Full-cycle Discrete Fourier Transform (DFT) is applied to estimate the fundamental frequency phasors.

TABLE I. THE PARAMETER OF SIMULATION SYSTEM

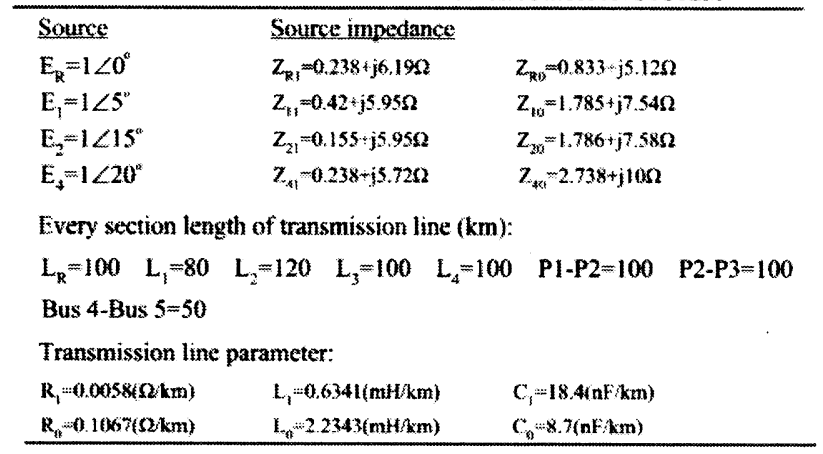

\section{B. Simulation results}

The simulation studies have been conducted with respect to various system and fault conditions. The error of fault location algorithm is evaluated as

Error $(\%)=\mid$ estimated location - actual location $\mid \times 100$
Some selected typical results are presented and discussed below.

\section{1) Cases studies}

Fig. 5(a) shows the post-fault response curves of the proposed indices for a phase-'abc' to ground fault (abc-g fault) between Bus 4 - Bus 5 line (external fault). The fault position is set at $40(\mathrm{~km})$ away from bus 4 , the fault resistance is $100 \mathrm{ohm}$ and fault inception angle is zero degree with respect to phase-'a' voltage waveform at bus 4 . From fig. 5(a), we observe that all of the four indices $D_{1}, D_{2}$, $\mathrm{D}_{3}, \mathrm{D}_{4}$ do not converge. Fig. 5(b) shows the post-fault response curves of the proposed indices for a phase-' $a$ ' to ground fault (a-g fault) in $\mathrm{L}_{4}$ section of test multi-terminal line (internal fault). The fault position is set at $90(\mathrm{~km})$ away from $\mathrm{P} 3$, the fault resistance is $100 \mathrm{ohm}$ and fault inception angle is zero degree with respect to phase-'a' voltage waveform at bus 4 . From fig. 5(b), we observe that all of the four indices $D_{1}, D_{2}, D_{3}, D_{4}$ converge to $1,2,3$, and 3.9, respectively. Therefore, based on Table I, the fault is located in $\mathrm{L}_{4}$. The fault location is 3.9039. The fault location error is $0.39 \%$.

To demonstrate the correctness of the developed faulted line section identification logic, 8 faults are simulated. The fault conditions are seen in Table II. In some tested cases, the fault resistance is $10 \mathrm{k} \mathrm{ohm}$. From the Table II, we observe that the four indices still can accurately locate the fault even when a high impedance fault occurs. Therefore,

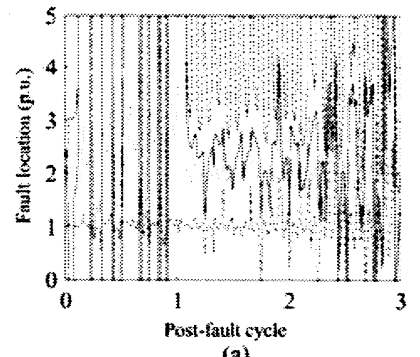

(a)

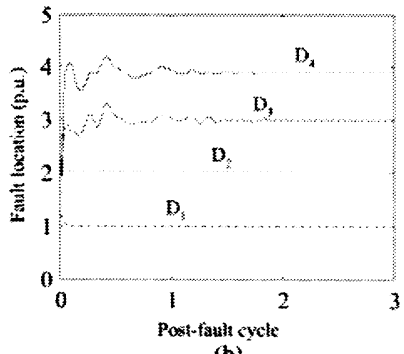

(b)
Fig. 5. The post-fault response curves of the proposed indices for an external fault and an internal fault.

TABLE II

THE PERFoRMANCE OF THE ALgORITHM FOR FIVE-TERMINAL LINES

\begin{tabular}{|c|c|c|c|c|c|c|c|c|c|}
\hline \multicolumn{2}{|c|}{ 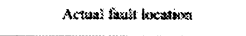 } & \multirow[b]{2}{*}{ fausle tyox } & \multicolumn{4}{|c|}{ 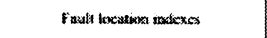 } & \multicolumn{3}{|c|}{ fruali sectorne selector } \\
\hline Fectoun & Fsulk poink & & Dt & $\mathrm{m} 2$ & bu & D4 & faull & 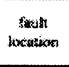 & $\begin{array}{l}\text { taudh } \\
\text { suration } \\
\text { erres } \%\end{array}$ \\
\hline Hax R.P. & $\begin{array}{c}20 \mathrm{kmm} \text { from } \mathrm{Pl} \\
\mathrm{b}_{1} * \mathrm{D}_{2} * \mathrm{D}_{3} * \mathrm{D}_{2} * \mathrm{aR}\end{array}$ & 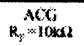 & 1. & and & - o.noted & a & & $0 \sin 364$ & 6.84 \\
\hline Zloux $1, P l$ & 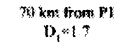 & 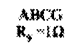 & 1.7002 & 1.0003 & 10000 & $1 . \cos x i x$ & & 173602 & $(10 \%$ \\
\hline $\operatorname{sen} 2 \cdot 82$ & 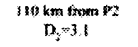 & $\mathbf{k}_{8 \rightarrow 10 \times 2}^{B C K_{3}}$ & a.sespen & 3.0986 & 200006 & 2.0004 & & 310 & 0.14 \\
\hline Sous 5. Py & 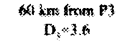 & $\stackrel{\text { Ans }}{n \rightarrow 502}$ & $0.900 / 26$ & 2.0172 & 3.6021 & 2.9000 & & $3 * 21$ & 0.21 \\
\hline Bus $4-p$, & $\begin{array}{l}\text { 90 } \mathrm{km} \text { frum } \mathrm{P3} \\
\mathrm{D}_{0}=34\end{array}$ & $\mathrm{R}_{r} \underset{\mathrm{AG}}{\mathrm{AG}}$ & 1,0002 & $2.03 * 2$ & 3.0003 & 29039 & & 39909 & 0.39 \\
\hline$p_{3} \cdot p_{2}$ & 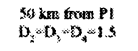 & $\mathrm{R}_{4} \times 16 \mathrm{~kg}$ & logews & 1.4999 & i.s & 1.4993 & & $1.49 \%$ & $n$ \\
\hline$p_{2}-p_{3}$ & $\begin{array}{c}30 \text { km Irom } m z \\
D_{1} \times D_{*} * 23\end{array}$ & $\mathrm{R}_{q} \times \sin$ & 1900 & 2.0078 & $2.29 \% 6$ & 2.3014 & & 2.2936 & nnt \\
\hline $\begin{array}{c}\text { Execra: } \\
\text { faxs: }\end{array}$ & 4) kns thom has 4 & $\underset{\mathrm{R}_{*}, \operatorname{AHCO}}{\mathrm{AHCO}}$ & $\cdots$ & $\ldots$ & $\ldots$ & $\ldots$ & 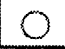 & 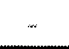 & $\ldots$ \\
\hline
\end{tabular}

TABLE III

THE StAtistical Results of THE Algorithm FOR THE TESTED LiNE 


\begin{tabular}{|c|c|c|c|c|}
\hline \multicolumn{2}{|c|}{ Actual fault location } & \multirow{2}{*}{$\begin{array}{l}\text { Total tested cases including } \\
\text { difierent fault type, } \\
\text { fault inception angle, } \\
\text { and fault resistance }\end{array}$} & \multirow{2}{*}{$\begin{array}{l}\text { The correct } \\
\text { number } \% \text { ) } \\
\text { of selected } \\
\text { fault section }\end{array}$} & \multirow{2}{*}{$\begin{array}{l}\text { Average } \\
\text { fault } \\
\text { location } \\
\text { error } \%\end{array}$} \\
\hline Fault section & $\begin{array}{l}\text { Fault point (\%) } \\
\text { length of the } \\
\text { section) }\end{array}$ & & & \\
\hline \multirow[t]{3}{*}{ Bus R-PI } & $10 \%$ trom $n$ & 32 & $32000 \%$; & 0.20 \\
\hline & $30 \%$ tront $m$ & 32 & $32(100 \%)$ & 0.18 \\
\hline & 400 trom $n$ & 32 & szunom? & 0.24 \\
\hline \multirow[t]{3}{*}{ Bus I-PI } & 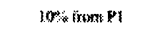 & 32 & $32(10 \% \%)$ & 0.32 \\
\hline & $\sec s$ frem $n$ & 32 & $320000 \%$ & 0.37 \\
\hline & 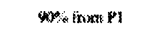 & 32 & $32(100 \%)$ & 0.24 \\
\hline \multirow[t]{3}{*}{ Bus 2 - P2 } & 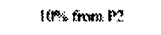 & 32 & $32000 \% 4$ & ons \\
\hline & 50 thent 12 & 32 & xatcotial & 0.56 \\
\hline & $x$ trom 1 & 32 & $321100 \%$ & 034 \\
\hline \multirow{3}{*}{ Bus $3-P_{3}$} & $10 \%$ prom as & 32 & $32(100 \%)$ & 0.16 \\
\hline & 500 froen P3 & 32 & $320100 \%$ & 0.19 \\
\hline & $90 \%$ from $P 3$ & 32 & $32(100 \%)$ & 0.30 \\
\hline \multirow[t]{3}{*}{ Bus 4-P3 } & $10 \%$ froma $\mathrm{P3}$ & 32 & $32(100 \%)$ & 0.25 \\
\hline & so\% trom os & 32 & $32(100 \%)$ & 0.13 \\
\hline & $90 \%$ from $p 3$ & 32 & $32(100 \%)$ & 0.22 \\
\hline \multirow{3}{*}{$\mathrm{PI}-\mathrm{P} 2$} & $10 \%$ from $p 1$ & 32 & $320100 \%$ & 0.56 \\
\hline & 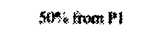 & 32 & $32(100 \%)$ & $0.2 x$ \\
\hline & Whe trom pl & 32 & $320100 \%$ & 0.48 \\
\hline \multirow[t]{3}{*}{ P2 - P3 } & $10 \%$ from $P 2$ & 32 & $32(100 \%)$ & 0.38 \\
\hline & $50 \%$ from 12 & 32 & $32(100 \%)$ & 0.65 \\
\hline & $\$(F)$ from $P 2$ & 32 & $32(1000 \%$ & 0.3 \\
\hline External fault & 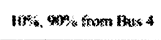 & 14 & tat $1000 \%$ & .. \\
\hline
\end{tabular}

Symbol ".-" represents an infinite value (external fault).

the algorithm is virtually unaffected by the fault path resistance.

\section{2) Statistical results}

The performance of the proposed algorithm under various fault conditions for transposed lines is presented in this subsection. Table III shows the statistical results of fault location. From the Table III, it is obvious that the proposed fault algorithm provides excellent performance under different fault conditions such as different fault types, fault positions, fault resistance, and fault inception angles. The average fault location error under various fault conditions is well below $1 \%$.

\section{CONCLUSIONS}

A new fault location algorithm for multi-terminal transmission lines is presented in this paper. Basic principles and detail formulation are also given. There is no particular restriction on the power source behind each terminal or the grounding system. The proposed algorithm is very simple, robust, and accurate for fault location. Only using indices, the fault can be accurately located. Special faulted line section identification and location selector is also developed and proved for multi-terminal lines. Extensive simulation studies verify that the performance of the method is very excellent and the average error of fault location is well less than $1 \%$ under various system and fault conditions.

The results demonstrate the feasibility and effectiveness of the proposed fault location algorithm for multi-terminal transmission lines.

\section{APPENDIX}

Consider a three-terminal line as depicted in fig. 2. The
PMUs are installed at buses $\mathrm{S}, \mathrm{R}$, and $\mathrm{T}$. Therefore, we can obtain three-terminal synchronized voltage and current phasors. There are three possible faulted line sections, which are $L_{R}, L_{S}$, and $L_{T}$ as shown in fig. 2. If we can know the faulted line section, then the two-terminal single-circuit algorithm can be directly applied to locate the fault by the synchronized data at the end of the faulted line and point $\mathrm{P}$, which can be estimated using the measured data at buses of other two non-faulted lines. For example, assume a fault occurs in $L_{R}$ as shown in fig. 2. The positive sequence voltage $V_{P}$ at point $P$ and current $I_{P}$ can be estimated by using the measured voltage and current phasors at buses $S$ and T. Thus, the analysis of the fault case can be reduced to be a two-terminal line system as shown in fig. 3. At this time, the fault point voltage $\mathrm{V}_{\mathrm{F}}$ can be estimated by the following equations:

$$
V_{F}=\frac{1}{2}\left(V_{R}+Z_{C} I_{R}\right) e^{\Gamma D_{1} L_{R}}+\frac{1}{2}\left(V_{R}-Z_{C} I_{R}\right) e^{-\Gamma D_{1} L_{R}}
$$

1)

$$
\begin{aligned}
V_{F}=\frac{1}{2} e^{-\Gamma L_{R}}\left(V_{P}+Z_{C} I_{P}\right) e^{\Gamma D_{1} L_{R}} \\
+\frac{1}{2} e^{\Gamma L_{R}}\left(V_{P}-Z_{C} I_{P}\right) e^{-\Gamma D_{1} L_{R}}
\end{aligned}
$$

2)

As shown in fig. 2, the $I_{P}$ can be estimated by the equation

$$
\begin{aligned}
\mathrm{I}_{\mathrm{P}}= & \mathrm{I}_{\mathrm{S}}^{\prime \prime}+\mathrm{I}_{\mathrm{T}}^{\prime \prime} \\
= & {\left[\frac{1}{2 \mathrm{Z}_{\mathrm{C}}} \mathrm{e}^{-\Gamma \mathrm{L}_{\mathrm{S}}}\left(\mathrm{V}_{\mathrm{S}}+\mathrm{Z}_{\mathrm{C}} \mathrm{I}_{\mathrm{S}}\right)-\frac{1}{2 \mathrm{Z}_{\mathrm{C}}} \mathrm{e}^{\Gamma \mathrm{L}_{\mathrm{S}}}\left(\mathrm{V}_{\mathrm{S}}-\mathrm{Z}_{\mathrm{C}} \mathrm{I}_{\mathrm{S}}\right)\right] } \\
& +\left[\frac{1}{2 \mathrm{Z}_{\mathrm{C}}} \mathrm{e}^{\left.-\Gamma \mathrm{L}_{\mathrm{T}}\left(\mathrm{V}_{\mathrm{T}}+\mathrm{Z}_{\mathrm{C}} \mathrm{I}_{\mathrm{T}}\right)-\frac{1}{2 Z_{\mathrm{C}}} \mathrm{e}^{\Gamma \mathrm{L}_{\mathrm{T}}}\left(\mathrm{V}_{\mathrm{T}}-\mathrm{Z}_{\mathrm{C}} \mathrm{I}_{\mathrm{T}}\right)\right]}\right.
\end{aligned}
$$

However, the $V_{P}$ can be calculated using the data at buses $\mathrm{S}$ or $\mathrm{T}$. The formula are expressed as

$$
\begin{aligned}
& \mathrm{V}_{\mathrm{P}}=\frac{1}{2} \mathrm{e}^{-\Gamma \mathrm{L}_{\mathrm{S}}}\left(\mathrm{V}_{\mathrm{S}}+\mathrm{Z}_{\mathrm{C}} \mathrm{I}_{\mathrm{S}}\right)+\frac{1}{2} \mathrm{e}^{\Gamma \mathrm{L}_{\mathrm{S}}}\left(\mathrm{V}_{\mathrm{S}}-\mathrm{Z}_{\mathrm{C}} \mathrm{I}_{\mathrm{S}}\right) \\
& \mathrm{V}_{\mathrm{P}}=\frac{1}{2} \mathrm{e}^{-\Gamma \mathrm{L}_{\mathrm{T}}}\left(\mathrm{V}_{\mathrm{T}}+\mathrm{Z}_{\mathrm{C}} \mathrm{I}_{\mathrm{T}}\right)+\frac{1}{2} \mathrm{e}^{\Gamma \mathrm{L}_{\mathrm{T}}}\left(\mathrm{V}_{\mathrm{T}}-\mathrm{Z}_{\mathrm{C}} \mathrm{I}_{\mathrm{T}}\right)
\end{aligned}
$$

Therefore, the two-terminal fault location algorithm described previously can be used to derive the fault location index. Based on this point of view, the fault location algorithm is developed and described below.

\section{1) A fault occurs in $L_{R}$}

We can use two subroutines to calculate the fault location. a) Subroutine1: $V_{P}$ is estimated using the data at bus $S$.

Substituting (A-3) and (A-4) into (A-2) and then equating fault point voltage $V_{F}$ from $(A-1)$ and $(A-2)$, the fault location is derived as:

$$
\mathrm{D}_{1}=\frac{\ln \left(\mathrm{N}_{1} / \mathrm{M}_{1}\right)}{2 \Gamma \mathrm{L}_{\mathrm{R}}}
$$

where $M_{1}$ and $N_{1}$ are expressed as 


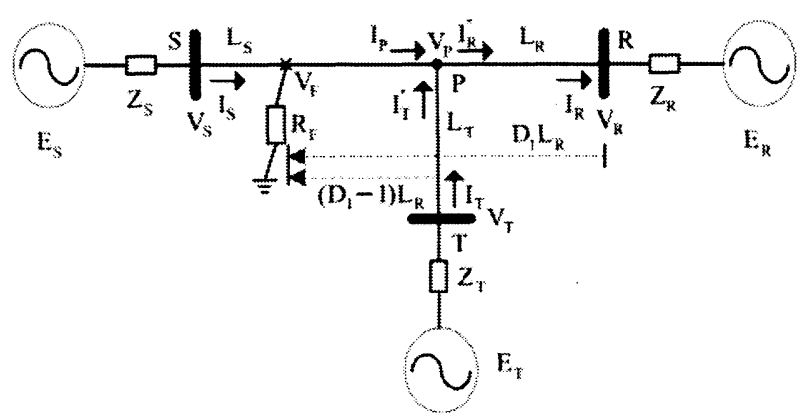

Fig. A-1. One-line diagram of a three-terminal transmission line under a fault occurs in $\mathrm{L}_{\mathrm{s}}$.

$$
\begin{aligned}
M_{1}= & {\left[\frac{1}{2} e^{-\Gamma\left(L_{S}+L_{R}\right)}\left(V_{S}+Z_{C} I_{S}\right)+\frac{1}{4} e^{-\Gamma\left(L_{T}+L_{R}\right)}\left(V_{T}+Z_{C} I_{T}\right)\right.} \\
& \left.-\frac{1}{4} e^{\Gamma\left(L_{T}-L_{R}\right)}\left(V_{T}-Z_{C} I_{T}\right)-\frac{1}{2}\left(V_{R}+Z_{C} I_{R}\right)\right] \quad(A-7) \\
N_{1}= & {\left[\frac{1}{2}\left(V_{R}-Z_{C} I_{R}\right)-\frac{1}{2} e^{\Gamma\left(L_{S}+L_{R}\right)}\left(V_{S}-Z_{C} I_{S}\right)\right.} \\
& \left.+\frac{1}{4} e^{-\Gamma\left(L_{T}-L_{R}\right)}\left(V_{T}+Z_{C} I_{T}\right)-\frac{1}{4} e^{\Gamma\left(L_{T}+L_{R}\right)}\left(V_{T}-Z_{C} I_{T}\right)\right]
\end{aligned}
$$

When a fault indeed occurs in $L_{R}$, the fault location index $\mathrm{D}_{1}$ converges to the interval of $[0,1]$ very fast.

b) Subroutine2: $V_{P}$ is estimated using the data at bus

$T$.

Similarly, combining (A-1), (A-2), (A-3), and (A-5), we can derive another fault location index $D_{2}$ which is given by

$$
\mathrm{D}_{2}=\frac{\ln \left(\mathrm{N}_{2} / \mathrm{M}_{2}\right)}{2 \Gamma \mathrm{L}_{\mathrm{R}}}
$$

where $\mathrm{M}_{2}$ and $\mathrm{N}_{2}$ are expressed as

$$
\begin{aligned}
\mathrm{M}_{2}= & {\left[\frac{1}{2} \mathrm{e}^{-\Gamma\left(\mathrm{L}_{\mathrm{T}}+\mathrm{L}_{\mathrm{R}}\right)}\left(\mathrm{V}_{\mathrm{T}}+\mathrm{Z}_{\mathrm{C}} \mathrm{I}_{\mathrm{T}}\right)+\frac{1}{4} \mathrm{e}^{-\Gamma\left(\mathrm{L}_{\mathrm{S}}+\mathrm{L}_{\mathrm{R}}\right)}\left(\mathrm{V}_{\mathrm{S}}+\mathrm{Z}_{\mathrm{C}} \mathrm{I}_{\mathrm{S}}\right)\right.} \\
& \left.-\frac{1}{4} \mathrm{e}^{\Gamma\left(\mathrm{L}_{\mathrm{S}}-\mathrm{L}_{\mathrm{R}}\right)}\left(\mathrm{V}_{\mathrm{S}}-\mathrm{Z}_{\mathrm{C}} \mathrm{I}_{\mathrm{S}}\right)-\frac{1}{2}\left(\mathrm{~V}_{\mathrm{R}}+\mathrm{Z}_{\mathrm{C}} \mathrm{I}_{\mathrm{R}}\right)\right] \\
\mathrm{N}_{2}= & {\left[\frac{1}{2}\left(\mathrm{~V}_{\mathrm{R}}-\mathrm{Z}_{\mathrm{C}} \mathrm{I}_{\mathrm{R}}\right)-\frac{1}{2} \mathrm{e}^{\Gamma\left(\mathrm{L}_{\mathrm{T}}+\mathrm{L}_{\mathrm{R}}\right)}\left(\mathrm{V}_{\mathrm{T}}-\mathrm{Z}_{\mathrm{C}} \mathrm{I}_{\mathrm{T}}\right)\right.} \\
& \left.+\frac{1}{4} \mathrm{e}^{-\Gamma\left(\mathrm{L}_{\mathrm{S}}-\mathrm{L}_{\mathrm{R}}\right)}\left(\mathrm{V}_{\mathrm{S}}+\mathrm{Z}_{\mathrm{C}} \mathrm{I}_{\mathrm{S}}\right)-\frac{1}{4} \mathrm{e}^{\Gamma\left(\mathrm{L}_{\mathrm{S}}+\mathrm{L}_{\mathrm{R}}\right)}\left(\mathrm{V}_{\mathrm{S}}-\mathrm{Z}_{\mathrm{C}} \mathrm{I}_{\mathrm{S}}\right)\right]
\end{aligned}
$$

If the fault indeed occurs in $L_{R}$, then the two fault location indices $D_{1}$ and $D_{2}$ will be equal and both converge to the interval of $[0,1]$.

2) A fault occurs in $L_{S}$

Assume a fault occurs in $L_{S}$ as shown in fig. A-1. The fault point voltage $V_{F}$ can be estimated using the measured phasors at bus $\mathrm{S}$ and the estimated equation is:

$$
\begin{aligned}
V_{F}= & \frac{1}{2} e^{-\Gamma L_{S}}\left(V_{S}+Z_{C} I_{S}\right) e^{\Gamma\left(D_{1}-1\right) L_{R}} \\
& +\frac{1}{2} e^{\Gamma L_{S}}\left(V_{S}-Z_{C} I_{S}\right) e^{-\Gamma\left(D_{1}-1\right) L_{R}}
\end{aligned}
$$

$$
\begin{aligned}
& =\frac{1}{2} e^{-\Gamma\left(L_{S}+L_{R}\right)}\left(V_{S}+Z_{C} I_{S}\right) e^{\Gamma D_{1} L_{R}} \\
& +\frac{1}{2} e^{\Gamma\left(L_{S}+L_{R}\right)}\left(V_{S}-Z_{C} I_{S}\right) e^{-\Gamma D_{1} L_{R}}
\end{aligned}
$$

The $\mathrm{V}_{\mathrm{F}}$ also can be obtained using the estimated phasors at point $\mathrm{P}$. Thus,

$$
\begin{aligned}
\mathrm{V}_{\mathrm{F}}= & \frac{1}{2}\left(\mathrm{~V}_{\mathrm{P}}+\mathrm{Z}_{\mathrm{C}} \mathrm{I}_{\mathrm{P}}\right) \mathrm{e}^{\Gamma\left(\mathrm{D}_{1}-1\right) \mathrm{L}_{\mathrm{R}}} \\
& +\frac{1}{2}\left(\mathrm{~V}_{\mathrm{P}}-\mathrm{Z}_{\mathrm{C}} \mathrm{I}_{\mathrm{P}}\right) \mathrm{e}^{-\Gamma\left(\mathrm{D}_{1}-1\right) \mathrm{L}_{\mathrm{R}}}
\end{aligned}
$$

where the voltage $V_{P}$ and current $I_{P}$ can be expressed as

$$
\begin{aligned}
\mathrm{V}_{\mathrm{P}} & =\frac{1}{2} \mathrm{e}^{\Gamma \mathrm{L}_{\mathrm{R}}}\left(\mathrm{V}_{\mathrm{R}}+\mathrm{Z}_{\mathrm{C}} \mathrm{I}_{\mathrm{R}}\right)+\frac{1}{2} \mathrm{e}^{-\Gamma \mathrm{L}_{\mathrm{R}}}\left(\mathrm{V}_{\mathrm{R}}-\mathrm{Z}_{\mathrm{C}} \mathrm{I}_{\mathrm{R}}\right) \\
\mathrm{I}_{\mathrm{P}} & =\mathrm{I}_{\mathrm{R}}^{\prime \prime}-\mathrm{I}_{\mathrm{T}}^{\prime \prime} \\
& =\left[\frac{1}{2 \mathrm{Z}_{\mathrm{C}}} \mathrm{e}^{\Gamma \mathrm{L}_{\mathrm{R}}}\left(\mathrm{V}_{\mathrm{R}}+\mathrm{Z}_{\mathrm{C}} \mathrm{I}_{\mathrm{R}}\right)-\frac{1}{2 \mathrm{Z}_{\mathrm{C}}} \mathrm{e}^{-\Gamma \mathrm{L}_{\mathrm{R}}}\left(\mathrm{V}_{\mathrm{R}}-\mathrm{Z}_{\mathrm{C}} \mathrm{I}_{\mathrm{R}}\right)\right] \\
- & {\left[\frac{1}{2 \mathrm{Z}_{\mathrm{C}}} \mathrm{e}^{-\Gamma \mathrm{L}_{\mathrm{T}}}\left(\mathrm{V}_{\mathrm{T}}+\mathrm{Z}_{\mathrm{C}} \mathrm{I}_{\mathrm{T}}\right)-\frac{1}{2 \mathrm{Z}_{\mathrm{C}}} \mathrm{e}^{\Gamma \mathrm{L}_{\mathrm{T}}\left(\mathrm{V}_{\mathrm{T}}-\mathrm{Z}_{\mathrm{C}} \mathrm{I}_{\mathrm{T}}\right)}\right] }
\end{aligned}
$$

Similarly, combining (A-12)-(A-15), we can derive the accurate fault location index. Moreover, we can easily prove that the fault location equations in this case are the same as (A-6)-(A-7). Therefore, the fault location index $D_{1}$ still can be applied to locate faults in $L_{S}$. However, the index $D_{1}$ will be greater than 1 .

As shown in fig. A-1, the $V_{P}$ can be estimated using the data from buses $\mathrm{R}$ and $\mathrm{T}$, respectively. Thus,

$$
V_{P}=\frac{1}{2}\left(V_{R}+Z_{C} I_{R}\right) e^{\Gamma L_{R}}+\frac{1}{2}\left(V_{R}-Z_{C} I_{R}\right) e^{-\Gamma L_{R}}
$$

and

$$
\mathrm{V}_{\mathrm{P}}=\frac{1}{2} \mathrm{e}^{-\Gamma \mathrm{L}_{\mathrm{T}}}\left(\mathrm{V}_{\mathrm{T}}+\mathrm{Z}_{\mathrm{C}} \mathrm{I}_{\mathrm{T}}\right)+\frac{1}{2} \mathrm{e}^{\Gamma \mathrm{L}_{\mathrm{T}}}\left(\mathrm{V}_{\mathrm{T}}-\mathrm{Z}_{\mathrm{C}} \mathrm{I}_{\mathrm{T}}\right)
$$

From (A-16) and (A-17), we obtain

$$
\begin{aligned}
& \frac{1}{2}\left(V_{R}-Z_{C} I_{R}\right)-\frac{1}{2} e^{\Gamma\left(L_{T}+L_{R}\right)}\left(V_{T}-Z_{C} I_{T}\right) \\
& \quad=\frac{1}{2} e^{-\Gamma L_{T}}\left(V_{T}+Z_{C} I_{T}\right) e^{\Gamma L_{R}}-\frac{1}{2}\left(V_{R}+Z_{C} I_{R}\right) e^{2 \Gamma L_{R}}
\end{aligned}
$$

Substituting (A-18) into (A-11) and then combining (A$10)$ and (A-11), we can obtain

$$
\frac{\mathrm{N}_{2}}{\mathrm{M}_{2}}=\mathrm{e}^{2 \Gamma \mathrm{L}_{\mathrm{R}}}
$$

From (A-9) and (A-19), the fault location index $D_{2}$ is

$$
\mathrm{D}_{2}=\frac{\ln \left(\mathrm{e}^{2 \Gamma \mathrm{L}_{\mathrm{R}}}\right)}{2 \Gamma \mathrm{L}_{\mathrm{R}}}=1
$$

Therefore, if the index $D_{2}$ is applied to locate faults occurring in $\mathrm{L}_{\mathrm{S}}$, it will converge to 1 .

3) A fault occurs in $L_{T}$

When a fault occurs in $L_{T}$ as shown in fig. A-2, the $V_{P}$ can be estimated using the data at buses $R$ and $S$, 
respectively. At

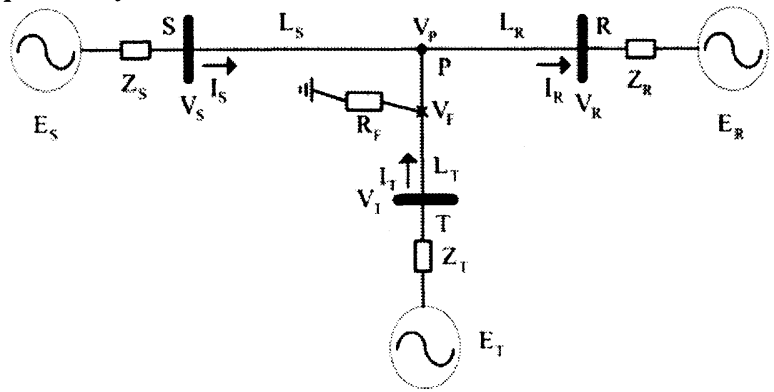

Fig. A-2. One-line diagram of a three-terminal transmission line under a fault occurs in $\mathrm{L}_{\mathrm{T}}$.

this time, we can obtain the equations, which are similar to (A-16)-(A-18), and the following relationship can be derived.

$$
\frac{\mathrm{N}_{1}}{\mathrm{M}_{1}}=\mathrm{e}^{2 \Gamma \mathrm{L}_{\mathrm{R}}}
$$

From (A-6) and (A-21), the location index $D_{1}$ is equal to 1 . We also can use the data at buses $R$ and $T$ to derive the fault location. Adopting the similar technique in (A-12)-(A$15)$, we can prove that the fault location equations in this case are the same as (A-9)-(A-11). However, the index $D_{2}$ will be greater than 1 . Therefore, the fault location indices $D_{1}$ and $D_{2}$ still can be applied to locate faults occurring in $L_{T}$.

\section{REFERENCES}

[1] D. Novosel, D. G. Hart, E. Udren, and M. M. Saha, "Fault Location Using Digital Relay Data", IEEE Computer Applications in Power, July 1995, pp. 45-50.

[2] L. Eriksson, M. M. Saha, and G. D. Rockefeller, " An Accurate Fault Locator with Compensation for Apparent Reactance in the Fault Resistance Resulting from Remote-End Infeed", IEEE Trans. on Power Apparatus and Systems, Vol. PAS-104, No. 2, February 1985, pp. 424-436.

[3] A. O. Ibe and B. J. Cory, "A Traveling Wave Based Fault Locator for Two- and Three-Terminal Networks", IEEE Trans. on Power Delivery, Vol. 1, No. 2, April 1986, pp. 283-288.

[4] M. Kezunovic, and B. Perunicic, "An Accurate Fault Location Algorithm Using Synchronized Sampling”, Electric Power Systems Research Journal, Vol. 29, No. 3, May 1994, pp. 161-169.

[5] A. A. Girgis, D. G. Hart, and W. L. Peterson, "A New Fault Location Technique for Two- and Three-Terminal Lines", IEEE Trans. on Power Delivery, Vol. 7, No. 1, July 1992, pp. 98-107.

[6] R. K. Aggarwal, D. V. Doury, A. T. Johns, and A. Kalam, "A Practicial Approach to Accurate Fault Location on Extra High Voltage Teed Feeders", IEEE Trans. on Power Delivery, Vol. 8, No. 3, July 1993, pp. 874-883.

[7] D. Novosel, D. G. Hart, E. Udren, and J. Garitty "Unsynchronized Two-Terminal Fault Location Estimation", IEEE Trans. on Power Delivery, Vol. 11, No. 1, January 1996, pp. 130-138.

[8] Masayuki Abe, Nobuo Otsuzuki, Tokuo Emura, and Masayasu Takeuchi, "development of a new fault location system for multiterminal single transmission lines", IEEE Trans. on Power Delivery, Vol. 10, No. 1, January 1995, pp. 159-168.

[9] T. Nagasawa, M. Abe, N. Otsuzuki, T. Emura, Y. Jikihara, and M. Takeuchi, "development of a new fault location algorithm for multiterminal two parallel transmission lines", IEEE Trans. on Power Delivery, Vol. 7, No. 3, July 1992, pp. 1516-1532.

[10] J.-A. Jiang, J.-Z. Yang, Y.-H. Lin, C.-W. Liu, and J.-C. Ma, "An Adaptive PMU Based Fault Detection/Location Technique for
Transmission Lines, Part I: Theory and Algorithms", IEEE Trans. on Power Delivery, Vol. 15, No. 2, April 2000, pp. 486-493.

[11] J.-A. Jiang, Y.-H. Lin, J.-Z. Yang, T.-M. Too, C.-W. Liu, "An Adaptive PMU Based Fault Detection/Location Technique for Transmission Lines, Part II: PMU Implementation and Performance Evaluation", IEEE Trans. on Power Delivery, Vol. 15, No. 4, October 2000, pp. 1136-1146.

[12] Ching-Shan Chen, and Chih-Wen Liu "Fast and Accurate Fault Detection/Location Algorithms for Double-Circuit/Three-Terminal Lines Using Phasor Measurement Units", Journal of the Chinese Institute of Engineers, Vol.26, No.3, pp.289-299, 2003.

[13] “Alternative Transient Program Rule Book", European EMTP Center, Leuven, Belgium, 1987.

\section{BIOGRAPHIES}

Kai-Ping Lien was born in Tainan, Taiwan in 1970. He received his B.S degrees in electrical engineering from National Sun Yat-Sen University in 1992. He is currently working toward his Ph.D. degree in Electrical Engineering Department of National Taiwan University.

Chih-Wen Liu (S'93-M'96-SM'02) was born in Taiwan, in 1964. He received the B.S. degree in electrical engineering from National Taiwan University (NTU), Taipei, Taiwan, and the M.S. and Ph.D. degrees in electrical engineering from Cornell University, Ithaca, NY, in 1987, 1992, and 1994, respectively.

Since 1994, he has been with NTU, where he is a Professor of electrical engineering. His main research interests include application of computer technology to power system monitoring, protection, and control. His other research interests include motor control and power electronics.

Joe-Air Jiang (M'01) was born in Tainei, Taiwan, in 1963. He received the M.S. and Ph.D. degrees in electrical engineering from National Taiwan University, Taipei, Taiwan, in 1990 and 1999, respectively. From 1990 to 2001, he was with Kuang-Wu Institute of Technology, Taipei, Taiwan.

Currently, he is an Associate Professor of bio-industrial mechatronics engineering at National Taiwan University, Taiwan. His areas of interest are in computer relaying, mechatronics, and bio-effects of electromagnetic wave.

Ching-Shan Chen was born in Taichung, Taiwan, in 1976. He received the B.S. degree in electrical engineering from National Taiwan University of Science and Technology, Taipei, Taiwan, and the M.S. and Ph.D. degrees in electrical engineering from National Taiwan University, Taipei, Taiwan, in 1998, 2000, and 2003, respectively. At present, he works at Industrial Technology Research Institute and his research interests include distributed generation systems and computer relaying.

Chi-Shan Yu was born in Taipei, Taiwan in 1966. He received his B.S. and M.S. degrees in electrical engineering from National Tsing Hua University in 1988 and 1990, and Ph.D. degree in electrical engineering from National Taiwan University in 2001. Since 2002, he came to National Defense University, Chung-Cheng Institute of Technology, where he is associate professor of electrical engineering. His research areas are in computer relaying, power system transient stability controller design and power electronics. 